\title{
A computational study of the 1,3-dipolar cycloaddition reaction mechanism for nitrilimines ${ }^{1}$
}

\author{
Robert C. Mawhinney, Heidi M. Muchall, and Gilles H. PesIherbe
}

\begin{abstract}
The [3+2] and [1+2] cycloaddition pathways between ethene and a series of 13 nitrilimines $\left(\mathrm{R}^{1} \mathrm{CNNR}{ }^{2}\right)$ have been examined by density functional theory [PBE0/6-311++G(2df,pd)] calculations. All reactions have low barriers ranging from $14.14\left(\mathrm{R}^{1}=\mathrm{CH}_{3}, \mathrm{R}^{2}=\mathrm{H}\right)$ to $1.01\left(\mathrm{R}^{1}=\mathrm{R}^{2}=\mathrm{F}\right) \mathrm{kcal} \mathrm{mol}^{-1}$, and large reaction exothermicities consistent with the transient nature of nitrilimines. The [3+2] and [1+2] transition-state structures are very similar, mainly differing in the relative orientation of their fragments and the newly forming $\mathrm{C}-\mathrm{C}$ bond distance, and exhibit only minor deviations from the structures of the reactants. Both reaction pathways are concerted and asynchronous, but the [1+2] reaction has a greater degree of asynchronicity. Examination of the frontier molecular orbitals reveals that both the $[3+2]$ and $[1+2]$ barrier heights are related to two sets of orbital interactions, with the interaction between the lowest unoccupied molecular orbital $\pi_{5}^{\mathrm{NN}}$ of nitrilimine and the highest occupied molecular orbital of ethene in common. The second interaction in both cases is carbene-like. A relationship between the weights of the 1,3-dipolar resonance contribution in the various nitrilimines and the corresponding [3+2] barrier heights was not found, but a good correlation could be found between the [1+2] barrier heights and both the 1,3-dipolar and carbene contributions. Inspection of the potential energy surface in the vicinity of the two transition states for the reaction between unsubstituted nitrilimine and ethene suggests that the observed [3+2] product is a result of an initial carbene-like approach of the two fragments followed by a ridge bifurcation that leads to the [3+2] product minimum.
\end{abstract}

Key words: nitrilimines, 1,3-dipole, carbene, [3+2] cycloaddition, [1+2] cycloaddition, density functional theory (DFT).

Résumé : Les réactions de cycloaddition [3+2] et [1+2] entre l'éthène et une série de treize nitrilimines $\left(\mathrm{R}^{1} \mathrm{CNNR}{ }^{2}\right)$ ont été étudiées par calculs de théorie de la fonctionelle de densité [PBE0/6-311++G(2df,pd)]. Les réactions sont caratérisées par des barrières variant de $14,14\left(\mathrm{R}^{1}=\mathrm{CH}_{3}, \mathrm{R}^{2}=\mathrm{H}\right)$ à $1,01\left(\mathrm{R}^{1}=\mathrm{R}^{2}=\mathrm{F}\right) \mathrm{kcal} \mathrm{mol}^{-1}$ et une forte exothermicité qui reflète la nature transitoire des nitrilimines. La structure des états de transition, très proche de celle des réactifs, est très semblable pour les réactions de cycloaddition [3+2] et [1+2] et ne diffère que par l'orientation relative des fragments et par la longueur de la liaison $\mathrm{C}-\mathrm{C}$ qui se forme au cours de la réaction. Les deux chemins de réactions sont concertés et aynchrones, avec une asynchronicité plus prononcée pour la réaction [1+2]. Les orbitales moléculaires frontières démontrent que les barrières de réaction [3+2] et [1+2] sont reliées à deux groupes d'interactions orbitalaires qui ont en commun l'interaction entre la plus basse orbitale moléculaire inoccupée $\pi_{5}^{\mathrm{NN}}$ de la nitrilimine et la plus haute orbitale moléculaire occupée de l'éthène. La seconde interaction est de type carbène pour les deux réactions. Une corrélation entre la contribution de la forme de résonance 1,3-dipolaire des nitrilimines et les barrières de réaction [3+2] correspondantes n'a pu être trouvée. Par contre, une forte corrélation est observée entre les barrières de réaction [1+2] et les contributions 1,3-dipolaires et carbèniques. L'examen de la surface d'énergie potentielle à proximité des deux états de transition de la réaction entre la nitrilimine non-substituée et l'éthène suggère que le produit [3+2] résulte d'une approche initiale des deux fragments de type carbénique, suivie d'une bifurcation à la crête de la surface qui conduit au minimum d'énergie potentielle du produit [3+2].

Mots clés : nitrilimines, 1,3-dipolaire, carbène, cycloaddition [3+2], cycloaddition [1+2], théorie de la fonctionelle de densité.

\section{Introduction}

The addition of a 1,3-dipole, a system of three atoms over which four $\pi$ electrons are distributed, to a dipolarophile, typically an alkene or alkyne, is the most commonly used synthetic method for forming five-membered heterocyclic molecules. The mechanism for these $[3+2]$ reactions has been the subject of numerous articles and remains an open problem in physical organic chemistry (1-7). Originally, Huisgen (8-10) proposed a concerted, single-step mechanism with the two new bonds partially formed at the transition state, akin to that for the Diels-Alder cycloaddition. Shortly thereafter, an alternative two-step mechanism involving a biradical intermediate was presented by Firestone

Received 23 June 2005. Published on the NRC Research Press Web site at http://canjchem.nrc.ca on 1 December 2005.

R.C. Mawhinney, H.M. Muchall, ${ }^{2}$ and G.H. Peslherbe. ${ }^{3}$ Centre for Research in Molecular Modeling and Department of Chemistry and Biochemistry, Concordia University, 7141 Sherbrooke Street West, Montreal, QC H4B 1R6, Canada.

${ }^{1}$ This article is part of a Special Issue dedicated to organic reaction mechanisms.

${ }^{2}$ Corresponding author (e-mail: muchall@alcor.concordia.ca).

${ }^{3}$ Corresponding author (e-mail: ghp@alcor.concordia.ca). 
Scheme 1.

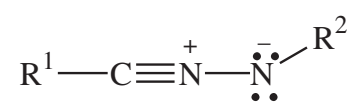

Propargylic
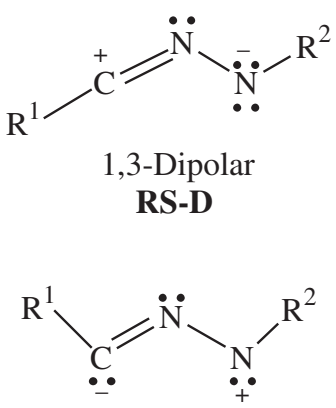

Reverse

1,3-dipolar

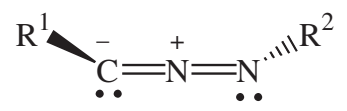

Allenic

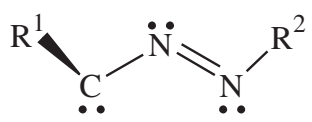

Carbenic RS-C

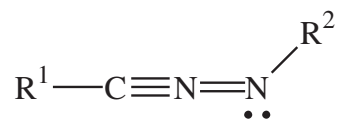

Hypervalent
(11-14). Since then, much work (1-7) has focused on distinguishing between the two mechanisms and, as Firestone originally alluded to (11), a duality of mechanism appears to exist. The majority of the initial explorations of Huisgen et al. (15-20) centered around the nitrilimine 1,3-dipole $\left(\mathrm{R}^{1} \mathrm{CNNR}^{2}\right)$ for which the cycloaddition reactions are commonly believed to proceed via the concerted mechanism ( 7 , $21,22)$. Interestingly, no theoretical studies of an alternative pathway have been reported, even though this 1,3-dipole is at the heart of the original mechanism debate $(9,11,23)$.

The nitrilimine 1,3-dipole is normally formed in situ as a transient, highly reactive species, which tends to dimerize, forming either dihydrotetrazines or bis(azo)ethenes, but in the presence of either electron-rich or electron-poor dipolarophiles, it readily undergoes [3+2] cycloadditions $(24$, 25). Stabilized nitrilimines also have been synthesized and they generally exhibit similar reactivity to their transient counterparts. Slight modifications of the substituents on the stabilized nitrilimine, though, have revealed that the philicity can be modified, with some nitrilimines acting strictly as nucleophiles and others as electrophiles $(25,26)$. A second important factor for the nitrilimine cycloaddition reactions is their regioselectivity, since the addition to unsymmetric dipolarophiles can result in two possible regioisomeric products. Nevertheless, nitrilimines appear to be highly selective with the newly formed bond to the carbon terminus typically with the less-substituted atom of the dipolarophile (24). Still, a recent study has revealed that changing the $\mathrm{C}$-substituent of nitrilimine, from $\mathrm{Br}$ to $\mathrm{H}$, results in an unexpected complete reversal in regioselectivity (27).

Employing resonance theory, Huisgen (28) explained the observed [3+2] reactivity in nitrilimines and related systems, and generalized the 1,3-dipole concept. For nitrilimines, sev- eral resonance structures have been invoked to explain their reactivity and electronic structure (Scheme 1) (28-31). In his original formulation, Huisgen (28) suggested that the electron sextet structures, the dipolar (RS-D) and carbenic (RSC) forms, make only small contributions to the electronic structure of any 1,3-dipole owing to the lack of octet stabilization, but it was still this minor contribution that directed the course of reaction. In a recent study $(32),{ }^{4}$ we evaluated the weights of various resonance contributions for a series of nitrilimines, using density functional methods combined with natural resonance theory (33-35), and found that the RS-D and RS-C structures were considerably more important than previously believed, and were even the dominant contributors in all systems studied. More interestingly, for some cases such as diaminonitrilimine $\left(\mathrm{R}^{1}=\mathrm{R}^{2}=\mathrm{NH}_{2}\right)$, RS$\mathrm{C}$ was by far the primary resonance form.

The most fundamental of cycloadditions, a [1+2] reaction, occurs between carbenes and alkenes forming cyclopropanes $(36,37)$. Many carbenes are ambiphilic, reacting with both electron-rich and electron-poor alkenes, but varying the substituents can induce either electrophilic or nucleophilic behaviour exclusively (38). The mechanism for this fundamental reaction has been extensively studied (39-43), and theoretical studies suggest that the reaction between singlet carbenes and alkenes is a highly asynchronous yet concerted process, which was recently confirmed by kinetic isotope effect experiments (41). Given the significant carbene character contribution to the electronic structure in nitrilimines for certain substituents, it may be possible to observe [1+2] type reactivity.

In this paper we explore the [3+2] and [1+2] cycloaddition reaction pathways (Scheme 2) between ethene and nitrilimine, examining the effects of $\mathrm{C}$-substitution, $\mathrm{N}$-substitution, and symmetric $\mathrm{C}$, N-disubstitution with $\mathrm{CH}_{3}, \mathrm{NH}_{2}, \mathrm{OH}$, and $\mathrm{F}$, and show that the $[1+2]$ reaction path is an integral part of the early stages of the $[3+2]$ mechanism. To the best of our knowledge, this is the first study of the $[1+2]$ reaction in nitrilimines and the first attempt to examine systematically the effects of nitrilimine substituents on the [3+2] reaction.

\section{Computational methods}

All calculations were carried out using the GAUSSIAN 98 suite of programs (44). The minima for all reactants and products, as well as transition-state (TS) stationary points, were obtained using the Perdew-Burke-Ernzerhof (PBE0) hybrid density functional $(45-47)$ and a relatively large 6$311++\mathrm{G}(2 \mathrm{df}, \mathrm{pd})$ basis set $(48,49)$. The nature of all stationary points was confirmed by vibrational analysis and the relative energies reported throughout include unscaled zeropoint energy corrections. A stability analysis was performed on all stationary points to confirm that a lower energy broken-symmetry solution did not exist. Additionally, for reactions of the unsubstituted nitrilimine, biradical structures were explicitly searched for, ${ }^{5}$ but in all calculations only closed shell structures could be obtained. Intrinsic reaction coordinate (IRC) calculations $(50,51)$, using mass-weighted

\footnotetext{
${ }^{4}$ R.C. Mawhinney, H.M. Muchall, and G.H. Peslherbe. To be submitted.

${ }^{5}$ Scans of the potential energy surface along the C5-C4-C3-N2 dihedral angle from $0^{\circ}$ to $180^{\circ}$, in increments of $15^{\circ}$, and the $\mathrm{C} 3-\mathrm{C} 4$ distance from 2.7 to $2.0 \AA$, in increments of $0.1 \AA$, were performed using the unrestricted PBE0 level of theory and a mixed guess for the wave function to alleviate orbital symmetry.
} 
Scheme 2.

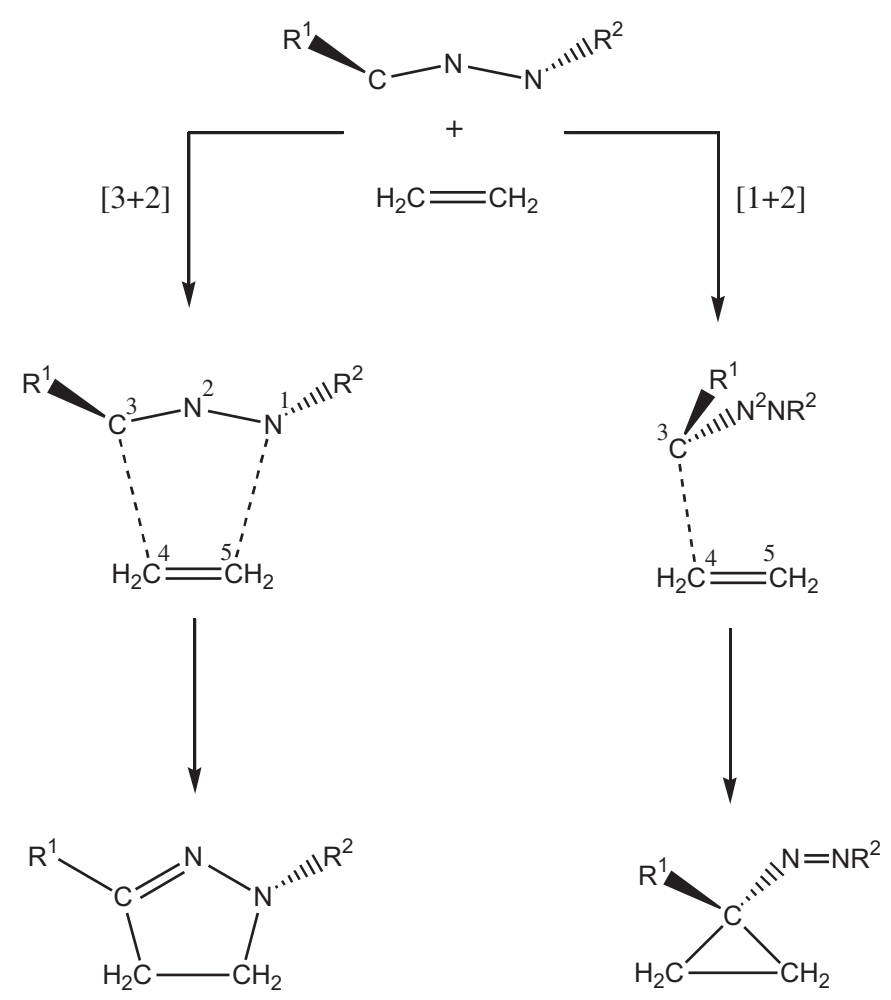

Cartesian coordinates, were performed to confirm the relationship between TS structures and reactants and products.

\section{Molecular geometries and energetics of cycloaddition reactions}

\section{Reactions of unsubstituted nitrilimine}

Results for the [3+2] and [1+2] cycloaddition reactions between ethene and unsubstituted nitrilimine are collected in Table 1 and in the Supplemental material. ${ }^{6}$ The results for the [3+2] reaction are in good agreement with a recent study at the B3LYP/6-31G(d) level of theory (7). The distances predicted by $\mathrm{PBE} 0 / 6-311++\mathrm{G}(2 \mathrm{df}, \mathrm{pd})$ are consistently smaller than the B3LYP values, by ca. $1 \%$ on average, but exhibit the same changes along the reaction coordinate. As expected, both methods predict a highly exothermic reaction and only a small barrier. With PBE0/6-311++G(2df,pd) the product is $5.1 \mathrm{kcal} \mathrm{mol}^{-1}$ more stable and the barrier is $0.38 \mathrm{kcal} \mathrm{mol}^{-1}$ lower than with B3LYP/6-31G(d). ${ }^{7}$ In the earlier study, single point calculations at the $\operatorname{CCSD}(\mathrm{T}) / 6$ $311 \mathrm{G}(\mathrm{d}, \mathrm{p})$ level, using B3LYP/6-31G(d) geometries, were also reported (7). Using the same approach with the PBE0/6$311++\mathrm{G}(2 \mathrm{df}, \mathrm{pd})$ geometries, we find an even better agreement, with the above differences reduced to 0.3 and $0.06 \mathrm{kcal} \mathrm{mol}^{-1}$, respectively. While there are no previous studies of the [1+2] cycloaddition reaction for comparison, the TS geometry involving the nitrilimine resembles those for the addition of dichlorocarbene and difluorocarbene to ethene (42) in that all cycloadditions are highly asynchronous.

The [3+2] reaction is kinetically favoured, with a reaction barrier that is ca. $4 \mathrm{kcal} \mathrm{mol}^{-1}$ smaller than that for the $[1+2]$ reaction. The $[1+2]$ and $[3+2]$ TSs are remarkably similar with respect to geometrical changes from the reactants. The main differences are the $\mathrm{C} 3-\mathrm{C} 4$ distance $(1.992$ vs. $2.290 \AA)$ and the $\mathrm{C} 5-\mathrm{C} 4-\mathrm{C} 3-\mathrm{N} 2$ dihedral angle $\left(88.5^{\circ}\right.$ vs. $\left.-0.3^{\circ}\right)$. The high asynchronicity of bond formation in the $[1+2] \mathrm{TS}$ is obvious, as both newly formed bonds have the same length in the product. Based on geometrical arguments, i.e., the ratio between the bond length in the product and the interatomic distance in the TS, bond formation is $76 \%$ complete for the $\mathrm{C} 3-\mathrm{C} 4$ and $60 \%$ complete for the $\mathrm{C} 3-\mathrm{C} 5$ bond at the TS. In the [3+2] TS structure, the $\mathrm{C} 3-\mathrm{C} 4$ distance is shorter than the N1-C5 distance, while the reverse is found in the product, demonstrating that the reaction is also significantly asynchronous, with the $\mathrm{C} 3-\mathrm{C} 4$ bond $66 \%$ formed and the $\mathrm{N} 1-\mathrm{C} 5$ bond $60 \%$ formed. While the $\mathrm{N} 1-\mathrm{C} 5$ bond in the $[3+2] \mathrm{TS}$ and the $\mathrm{C} 3-\mathrm{C} 5$ bond in the [1+2] TS are formed to the same extent, $\mathrm{C} 3-\mathrm{C} 4$ bond formation has proceeded further in the $[1+2] \mathrm{TS}$, consistent with the Hammond postulate (52), where a later transition state is associated with a higher barrier and a less exothermic reaction (the relative energies for the two products $\left(\Delta^{2}\right.$-pyrazoline and azocyclopropane) are -60.5 and $-35.5 \mathrm{kcal} \mathrm{mol}^{-1}$, respectively).

\section{Reactions of substituted nitrilimines}

Naturally, all [3+2] products studied are more stable than their $[1+2]$ counterparts and substitution increases the exothermicity of both reactions. ${ }^{6}$ However, as observed for unsubstituted nitrilimine, both reaction paths have rather small barriers and fall under kinetic control (Table 1). To explore the effects of substitution, selected geometric parameters for the TS structures and relative barrier heights $\left(E_{\mathrm{a}}\right)$ for the two cycloaddition pathways are given in Table 1 for substituted nitrilimines. Three of the TSs for the [1+2] reaction path could not be located (see the following). Substitution does not dramatically affect the geometry of the CNN backbone from that observed in the parent nitrilimine $(32)^{4}$, consistent with an early TS. The C5-C4-C3-N2 dihedral angle in the $[3+2] \mathrm{TSs}$ is relatively unaffected, with only Csubstitution by $\mathrm{NH}_{2}$ causing any significant deviation from $0^{\circ}$, while in the $[1+2] \mathrm{TSs}$ it ranges from $95.6^{\circ}\left(\mathrm{R}^{1}=\mathrm{CH}_{3}\right.$, $\mathrm{R}^{2}=\mathrm{H}$ or $\left.\mathrm{CH}_{3}\right)$ to $56.2^{\circ}\left(\mathrm{R}^{1}=\mathrm{R}^{2}=\mathrm{F}\right)$. The largest effect of substitution is on the newly forming $\mathrm{C} 3-\mathrm{C} 4$ bond, increasing the internuclear separation by as much as $0.245 \AA$ in the $[3+2]$ TSs and $0.252 \AA$ in the $[1+2]$ TSs. The increase in separation between the two fragments generally results in a smaller $E_{\mathrm{a}}$. In the majority of cases, the [3+2] reaction remains kinetically favoured but, as also observed for the products, ${ }^{6}$ substitution at $\mathrm{N}$ has a larger effect on the $[1+2]$ reaction, lowering the $E_{\mathrm{a}}$ by as much as $8 \mathrm{kcal} \mathrm{mol}^{-1}$. This results in two cases $\left(\mathrm{R}^{1}=\mathrm{H}, \mathrm{R}^{2}=\mathrm{OH}\right.$ and $\left.\mathrm{R}^{1}=\mathrm{H}, \mathrm{R}^{2}=\mathrm{F}\right)$ in which the $[1+2]$ reaction is favoured and two cases $\left(R^{1}=\right.$ $\mathrm{H}, \mathrm{R}^{2}=\mathrm{NH}_{2}$ and $\mathrm{R}^{1}=\mathrm{R}^{2}=\mathrm{F}$ ), where the two barriers are within $1 \mathrm{kcal} \mathrm{mol}^{-1}$.

\footnotetext{
${ }^{6}$ Supplementary data for this article are available on the Web site or may be purchased from the Depository of Unpublished Data, Document Delivery, CISTI, National Research Council Canada, Ottawa, ON K1A 0R6, Canada. DUD 4050. For more information on obtaining material refer to http://cisti-icist.nrc-cnrc.gc.ca/irm/unpub_e.shtml. Table S1 of the supplemental material contains selected product data.

${ }^{7}$ These differences are with respect to energies without zero-point energy corrections.
} 
Table 1. Relative energies ( $\left.\mathrm{kcal} \mathrm{mol}^{-1}\right)$, selected bond lengths $(\AA)$, and dihedral angles $\left(^{\circ}\right)$ of the transition states of [3+2] and [1+2] cycloaddition between ethene and substituted nitrilimines.

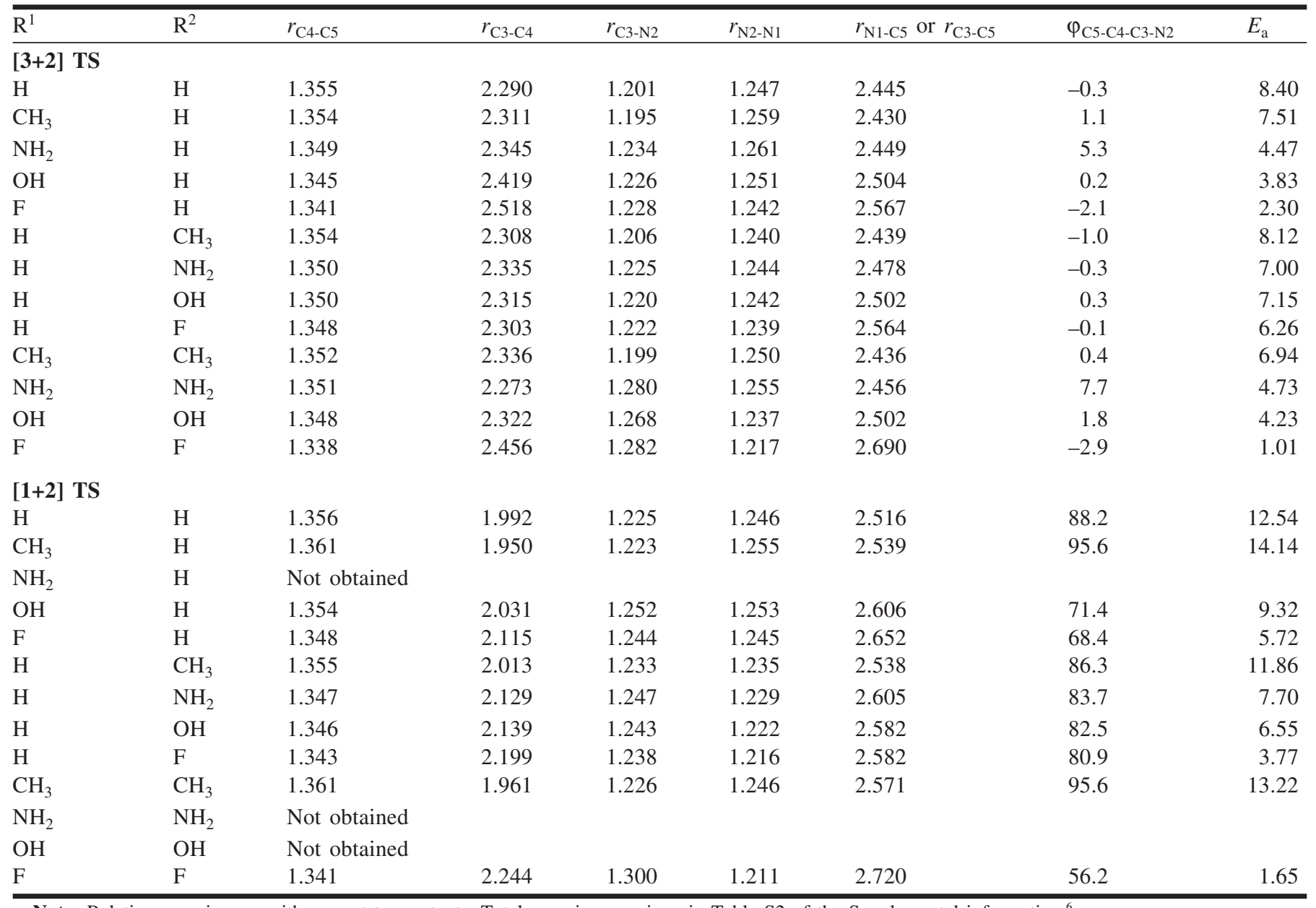

Note: Relative energies are with respect to reactants. Total energies are given in Table S2 of the Supplemental information. ${ }^{6}$

In all cases, the $\mathrm{C} 3-\mathrm{C} 4$ bond is formed to a larger extent than either the N1-C5 bond in the $[3+2]$ TS or the $\mathrm{C} 3-\mathrm{C} 5$ bond in the $[1+2] \mathrm{TS}$, demonstrating that both reactions remain asynchronous for substituted nitrilimines. The degree of asynchronicity, as measured by the difference in the extent of formation of the two new bonds, varies from $8 \%$ $\left(\mathrm{R}^{1}=\mathrm{H}, \mathrm{R}^{2}=\mathrm{F}\right)$ to $2 \%\left(\mathrm{R}^{1}=\mathrm{F}, \mathrm{R}^{2}=\mathrm{H}\right)$ in the [3+2] $\mathrm{TS}$ and from $18 \%\left(\mathrm{R}^{1}=\mathrm{CH}_{3}, \mathrm{R}^{2}=\mathrm{H}\right.$ or $\left.\mathrm{CH}_{3}\right)$ to $10 \%\left(\mathrm{R}^{1}=\mathrm{H}, \mathrm{R}^{2}=\right.$ $\mathrm{F})$ in the $[1+2] \mathrm{TS}$. As expected, all [1+2] reactions are more asynchronous than their [3+2] analogs (41) and, like the reactions of the unsubstituted nitrilimine, the N1-C5 bond of the [3+2] TS and the C3-C5 bond of the [1+2] TS have virtually the same degree of formation, differing by no more than $2 \%$ with respect to one another. However, the extent of $\mathrm{C} 3-\mathrm{C} 4$ bond formation in the two TS structures is affected differently by substitution. In the majority of cases, the difference in \% $\mathrm{C} 3-\mathrm{C} 4$ bond formation between the two TS structures is ca. $11 \%$, but in four systems $\left(\mathrm{R}^{1}=\mathrm{H}, \mathrm{R}^{2}=\right.$ $\mathrm{NH}_{2} ; \mathrm{R}^{1}=\mathrm{H}, \mathrm{R}^{2}=\mathrm{OH} ; \mathrm{R}^{1}=\mathrm{H}, \mathrm{R}^{2}=\mathrm{F}$; and $\mathrm{R}^{1}=\mathrm{R}^{2}=\mathrm{F}$ ) the difference is no more than $6 \%$.

According to the Hammond postulate, the reaction rate should be related to the position of the transition state along the reaction coordinate $(52)$. The reaction coordinate for carbene cycloadditions, as defined by Keating et al. (41), is the distance between the carbene carbon and the midpoint of
Scheme 3.
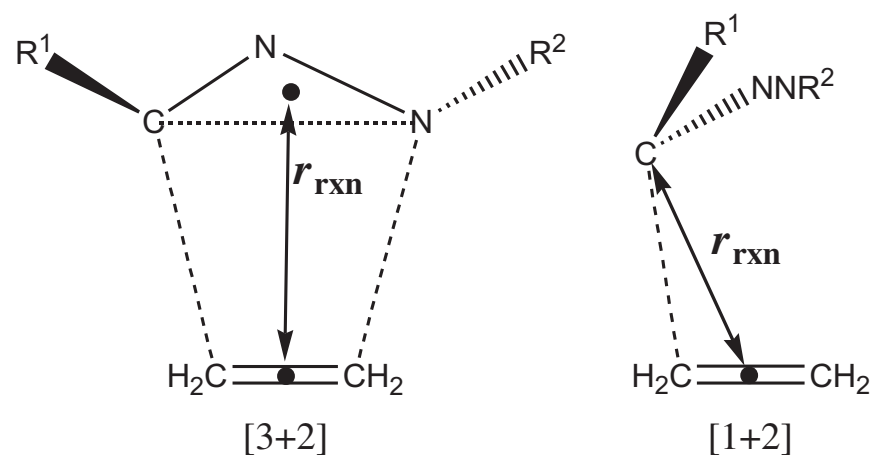

the alkene double bond. Similarly, the reaction coordinate for the $[3+2]$ cycloaddition reaction can be defined as the distance between the $\mathrm{C} 3-\mathrm{N} 2-\mathrm{N} 1$ incentre (the geometric midpoint of the C3-N2-N1 fragment) and the midpoint of the alkene bond. We will use these two approximate reaction coordinates, denoted $r_{\operatorname{rxn}}$ (Scheme 3), for the [3+2] and [1+2] reactions. The relationship between $E_{\mathrm{a}}$ and $r_{\mathrm{rxn}}$ for the various $[3+2]$ and $[1+2]$ reactions are shown in Fig. 1. For the $[3+2]$ reaction, the linear correlation coefficient $\left(r^{2}=\right.$ 0.837 ) suggests that $r_{\text {rxn }}$ captures only part of the full reac- 
Fig. 1. The relationship between: $(a)$ the $[3+2] E_{\mathrm{a}}$ and the corresponding $r_{\mathrm{rxn}}$ coordinate at the transition state; $(b)$ the $[1+2] E_{\mathrm{a}}$ and the corresponding $r_{\mathrm{rxn}}$ coordinate at the transition state; and (c) the $[1+2] E_{\mathrm{a}}$ and the $r_{\mathrm{C} 3-\mathrm{C} 4}$ coordinate at the transition state. See Scheme 3 for the definitions of $r_{\text {rxn }}$.
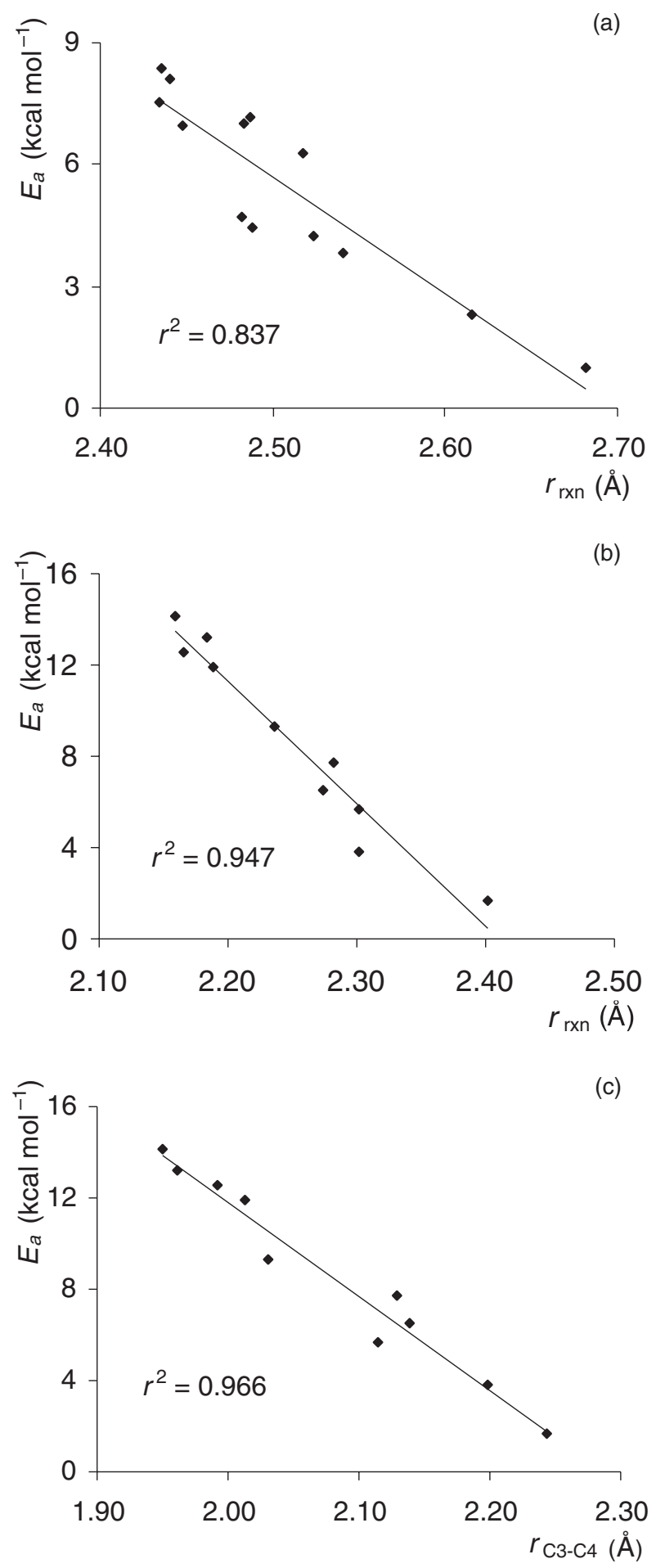

tion coordinate, yet $r_{\text {rxn }}$ is considerably more representative of the reaction than either $r_{\mathrm{N} 1-\mathrm{C} 5}$ or $r_{\mathrm{C} 3-\mathrm{C} 4}$, which correlate poorly with $E_{\mathrm{a}}\left(r^{2}=0.56\right.$ and 0.60 , respectively). For the $[1+2]$ reaction, the correlation coefficient $\left(r^{2}=0.947\right)$ indicates that $r_{\text {rxn }}$ captures the majority of the features of the full
Scheme 4.
$[3+2]$

HOMO

(1)

LUMO<smiles>O=P(O)(O)O</smiles><smiles>O=CO</smiles>

LUMO

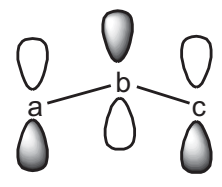

HOMO
$[1+2]$
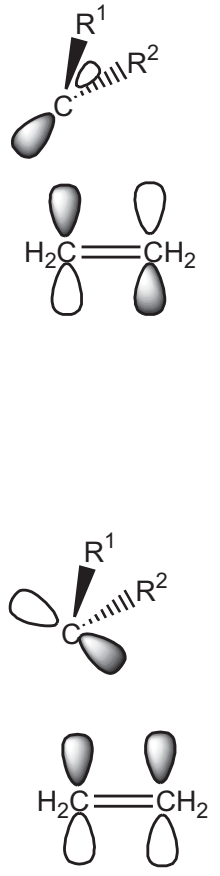

reaction coordinate. However, the correlation between $E_{\mathrm{a}}$ and $r_{\mathrm{C} 3-\mathrm{C} 4}$ is even better $\left(r^{2}=0.966\right.$, Fig. $\left.1 c\right)$, suggesting that the $[1+2]$ reaction is fully controlled by the approach of the nitrilimine carbon to only one ethene carbon atom.

\section{Properties governing nitrilimine reactivity}

According to the Hammond postulate (52), the low barrier heights and large reaction exothermicities indicate that both reactions are characterized by early transition states. This suggests that variations in reactivity largely depend on the properties of the reactants. Accordingly, in this section we examine the relationship between the properties of nitrilimines and their reactivity.

\section{Frontier molecular orbitals}

Frontier molecular orbital theory (FMO) has been extensively used to explain reactivity and regioselectivity in both [3+2] 1,3-dipolar $(53,54)$ and $[1+2]$ carbene (55) cycloaddition reactions. Simplified representations of the important molecular orbital interactions between the HOMO (highest occupied molecular orbital) and LUMO (lowest unoccupied molecular orbital) of ethene and either a dipole (a-b-c) or a carbene $\left(\mathrm{R}^{1}-\mathrm{C}-\mathrm{R}^{2}\right)$ are given in Scheme 4. As noted in previous studies, the major effect of substitution is a change in orbital energy, while the orbital shapes retain the same qualitative features $(54,56)$. To identify the proper orbitals of nitrilimine involved in the two reactions, the four highest occupied and two lowest unoccupied Kohn-Sham orbitals of unsubstituted nitrilimine are shown in Fig. 2. All have pseudo- $\pi$ symmetry (there is no strict $\sigma-\pi$ separation in the $C_{1}$ symmetrical molecules) and can be characterized as either $\pi^{\mathrm{CN}}$ or $\pi^{\mathrm{NN}}$. According to Scheme 4, the nitrilimine 
orbitals involved in the [3+2] interactions are $\pi_{4}^{\mathrm{NN}}$ and $\pi_{5}^{\mathrm{NN}}$, and those for the [1+2] interactions are $\pi_{4}^{\mathrm{NN}}$ and $\pi_{6}^{\mathrm{CN}}$. Unlike carbenes, which are restricted to one occupied $\mathrm{sp}^{2}$ orbital and one unoccupied $\mathrm{p}$ orbital on carbon, nitrilimines have two additional molecular orbitals $\left(\pi_{3}^{\mathrm{CN}}\right.$ and $\left.\pi_{5}^{\mathrm{NN}}\right)$ with the correct orientation for the [1+2] cycloaddition reaction. Therefore, $\pi_{5}^{\mathrm{NN}}$ may interact as LUMO and $\pi_{3}^{\mathrm{CN}}$ as HOMO with the corresponding ethene orbitals in a $[1+2]$ fashion. These additional interactions, along with the typical [1+2] and [3+2] interactions for the addition of nitrilimine to ethene, are displayed in Scheme 5.

Both nitrilimines and carbenes are generally described as ambiphilic, reacting with both electron-rich and electronpoor alkenes, but varying substituents can induce either exclusive electrophilic or nucleophilic behaviour $(24,25,37$, 38). In FMO terms, electrophilic behaviour is attributed to systems where the $\mathrm{HOMO}_{\text {dipolarophile }}-\mathrm{LUMO}_{\text {dipole }}$ energy difference is smaller, nucleophilic behaviour to systems where the $\mathrm{HOMO}_{\text {dipole }}-\mathrm{LUMO}_{\text {dipolarophile }}$ energy difference is smaller, and ambiphilic behaviour corresponds to situations in which both energy differences are similar $(53,54)$. The energy differences associated with the four main orbital interactions (A-D, Scheme 5) between ethene and the various nitrilimines are given in Table 2 . In the majority of cases, the smallest energy difference is $\Delta E_{\mathrm{B}}$, but in four systems $\left(\mathrm{R}^{1}=\mathrm{OH}, \mathrm{R}^{2}=\mathrm{H} ; \mathrm{R}^{1}=\mathrm{F}, \mathrm{R}^{2}=\mathrm{H} ; \mathrm{R}^{1}=\mathrm{R}^{2}=\mathrm{OH}\right.$; and $\left.\mathrm{R}^{1}=\mathrm{R}^{2}=\mathrm{F}\right) \Delta E_{\mathrm{C}}$ is lower, and only in one $\left(\mathrm{R}^{1}=\mathrm{H}, \mathrm{R}^{2}=\right.$ $\mathrm{F}), \Delta E_{\mathrm{D}}$ is the smallest. Despite the swap in the character of the lowest energy orbital interaction, the next lowest orbital energy difference is generally within ca. $1 \mathrm{eV}$ and corresponds to an interaction of opposite character, consistent with the known ambiphilic reactivity of most nitrilimines (24). Exceptions where the two lowest energy interactions exhibit the same character appear for $N$-fluoro substituted nitrilimines $\left(\mathrm{R}^{1}=\mathrm{H}\right.$ or $\left.\mathrm{F}, \mathrm{R}^{2}=\mathrm{F}\right)$.

The relative energy of a transition state for a reaction with a small barrier and large reaction exothermicity can be predicted from the relative energy of a weakly interacting complex. The original derivation of the equation for this interaction energy was given by Salem and contained three terms, representing closed shell interactions, coulombic interactions, and orbital overlap (57-59). In many implementations, though, the first two terms are commonly neglected and the relative energy of the complex is predicted from the orbital overlap alone $(53,54)$. The orbital interaction terms for a general [3+2] and $[1+2]$ reaction with ethene (Scheme 4) are given in eqs. [1] and [2], respectively,

$$
\begin{aligned}
& \Delta E= \frac{\left[C_{\mathrm{HOMO}(\mathrm{C} 4)} C_{\mathrm{LUMO}(\mathrm{a})}+C_{\mathrm{HOMO}(\mathrm{C} 5)} C_{\mathrm{LUMO}(\mathrm{c})}\right]^{2} \beta^{2}}{\varepsilon_{\mathrm{HOMO}(\mathrm{Ethene})}-\varepsilon_{\mathrm{LUMO}(\text { Dipole })}} \\
&+\frac{\left[C_{\mathrm{HOMO}(\mathrm{a})} C_{\mathrm{LUMO}(\mathrm{C} 4)}+C_{\mathrm{HOMO}(\mathrm{c})} C_{\mathrm{LUMO}(\mathrm{C} 5)}\right]^{2} \beta^{2}}{\varepsilon_{\mathrm{HOMO}(\text { Dipole })}-\varepsilon_{\mathrm{LUMO}(\text { Ethene) }}}
\end{aligned}
$$

$$
\begin{aligned}
\Delta E & =\frac{\left[C_{\mathrm{HOMO}(\mathrm{C} 4)} C_{\mathrm{LUMO}(\mathrm{C})}+C_{\mathrm{HOMO}(\mathrm{C} 5)} C_{\mathrm{LUMO}(\mathrm{C})}\right]^{2} \beta^{2}}{\varepsilon_{\mathrm{HOMO}(\mathrm{Ethene})}-\varepsilon_{\mathrm{LUMO}(\mathrm{Carbene})}} \\
+ & \frac{\left[C_{\mathrm{HOMO}(\mathrm{C})} C_{\mathrm{LUMO}(\mathrm{C} 4)}+C_{\mathrm{HOMO}(\mathrm{C})} C_{\mathrm{LUMO}(\mathrm{C} 5)}\right]^{2} \beta^{2}}{\varepsilon_{\mathrm{HOMO}(\text { Carbene) }}-\varepsilon_{\mathrm{LUMO}(\text { Ethene })}}
\end{aligned}
$$

Fig. 2. Two representations of the six $\pi$-type molecular orbitals (0.05 au isosurface) of unsubstituted nitrilimine along with orbital energies.

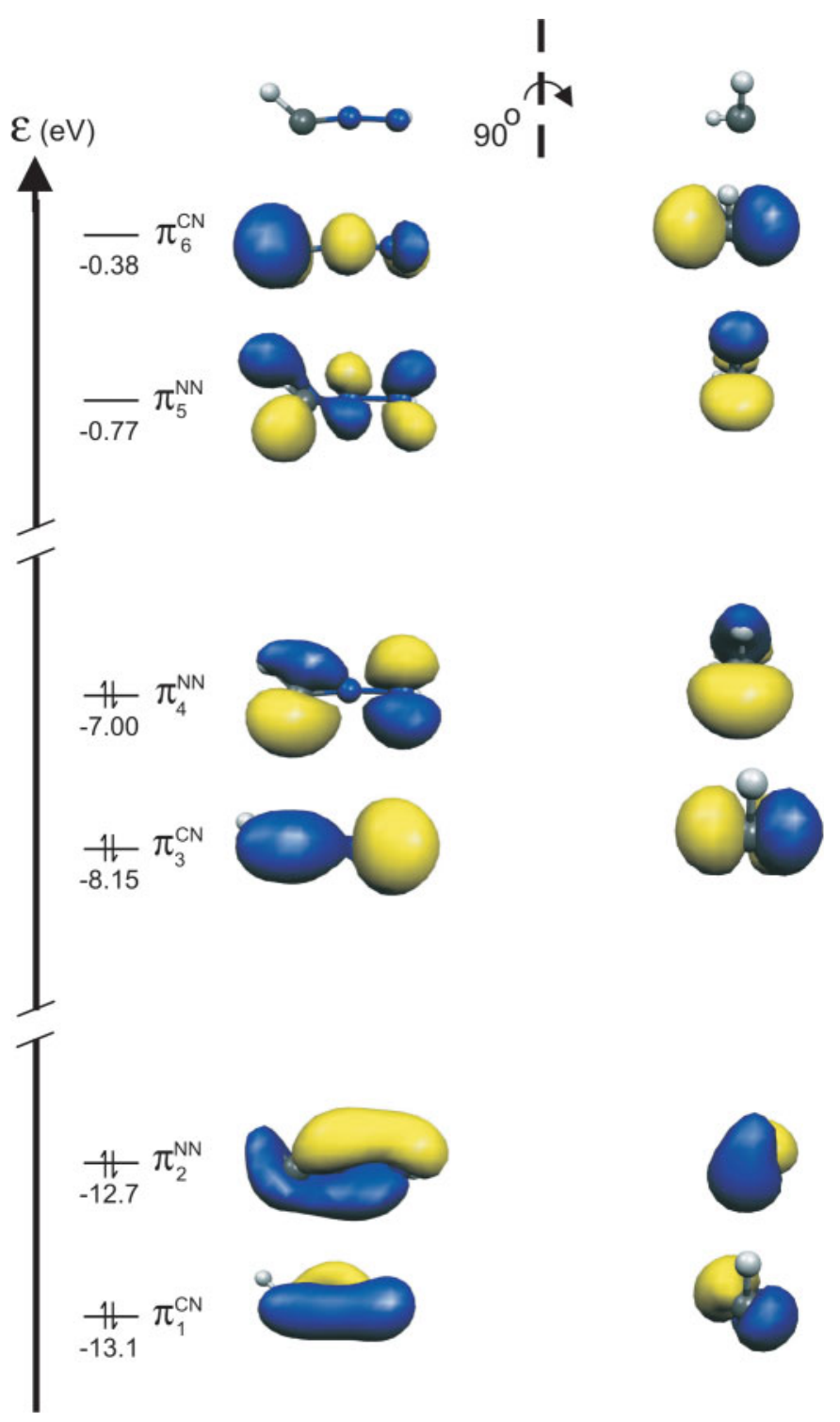

where the denominator is the energy difference between the FMOs involved in the interaction and the numerator contains products of the atomic orbital coefficients at the centres where the two bonds are formed, and the resonance integral $(\beta)$ is a measure of the interaction strength. These equations can readily be expanded to include additional orbital interactions. Since the ethene orbitals are the same throughout and the shapes of the nitrilimine orbitals are qualitatively similar (32), one may assume that the atomic orbital coefficients are relatively constant, and their products may be approximated by a general factor $(K)$. Additionally, the distance between the interacting centres is moderately invariant (Table 1), and so $\beta$ may also be considered constant. A similar approach has been used to explain the effects of substitution on the reactivity of phenylazide (54). Applying these approximations results in simplified eqs. [3] and [4] for the [3+2] and [1+2] interaction energies, respectively. 
Scheme 5.
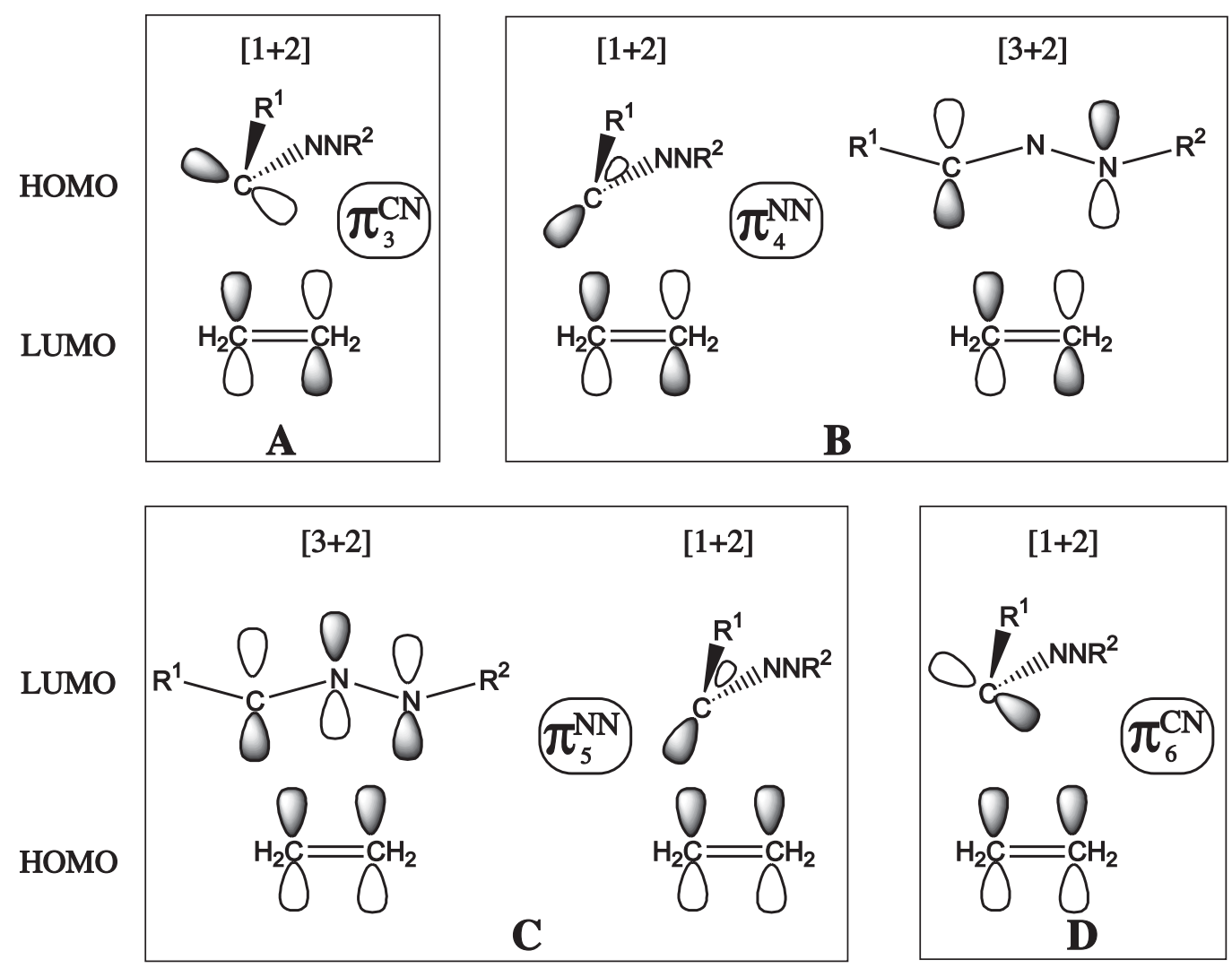

$$
\begin{aligned}
& \Delta E^{[3+2]}=K \beta^{2}\left[\frac{1}{\varepsilon_{\text {HOMO(Ethene) }}-\varepsilon_{\mathrm{LUMO}(\text { Dipole) }}}+\frac{1}{\varepsilon_{\mathrm{HOMO}(\text { Dipole) }}-\varepsilon_{\mathrm{LUMO}(\text { Ethene) }}}\right] \\
& \Delta E^{[1+2]}=K \beta^{2}\left[\frac{1}{\varepsilon_{\mathrm{HOMO}(\text { Ethene) }}-\varepsilon_{\mathrm{LUMO}(\text { Carbene) }}}+\frac{1}{\varepsilon_{\text {HOMO(Carbene) }}-\varepsilon_{\mathrm{LUMO}(\text { Ethene) }}}\right]
\end{aligned}
$$

Following a systematic examination of the relationship between the barrier heights for both reaction types and all possible combinations of orbital interactions (Scheme 5), we present the best correlations in Figs. $3 a$ and $3 b$. Naturally, for the [3+2] reaction, the barrier heights correlate with $1 / \Delta E_{\mathbf{B}}+1 / \Delta E_{\mathbf{C}}\left(r^{2}=0.728\right)$. While a somewhat better correlation $\left(r^{2}=0.790\right)$ is achieved for $1 / \Delta E_{\mathbf{C}}$ alone, suggesting that $\pi_{5}^{\mathrm{NN}}$ plays a key role in [3+2] reactivity, the best correlation $\left(r^{2}=0.797\right)$ involves $1 / \Delta E_{\mathbf{C}}$ in conjunction with $1 / \Delta E_{\mathbf{A}}$, formally a [1+2] orbital interaction (Fig. 3a, eq. [5]). The best correlation $\left(r^{2}=0.794\right)$ for the [1+2] reaction barrier is for $1 / \Delta E_{\mathbf{C}}+1 / \Delta E_{\mathbf{D}}$, both of which involve an unoccupied orbital of nitrilimine interacting with the HOMO of ethene (Fig. 3b, eq. [6]). As the relationships in eqs. [5] and [6] are linear, the differences in barrier heights $\left(\Delta E_{\mathrm{a}}\right)$ between the [1+2] $E_{\mathrm{a}}$ and the [3+2] $E_{\mathrm{a}}$ can be approximated by eq. [7] for which results are plotted in Fig. 3c. Since the assumption of a constant numerator can not be expected to hold in the combined relationship, the correlation is slightly worse $\left(r^{2}=0.740\right)$ than those for the individual relationships. None of the other potential combinations of individual relationships results in a reasonable correlation.

$$
E_{\mathrm{a}}^{[3+2]}=m\left[\frac{1}{\varepsilon_{\mathrm{HOMO}(\text { Ethene) }}-\varepsilon_{\mathrm{LUMO}\left(\pi_{5}^{\mathrm{NN}}\right)}}+\frac{1}{\varepsilon_{\mathrm{HOMO}\left(\pi_{3}^{\mathrm{CN}}\right)}-\varepsilon_{\mathrm{LUMO}(\text { Ethene) }}}\right]+b
$$

$$
E_{\mathrm{a}}^{[1+2]}=m\left[\frac{1}{\varepsilon_{\mathrm{HOMO}(\text { Ethene) }}-\varepsilon_{\mathrm{LUMO}\left(\pi_{5}^{\mathrm{NN}}\right)}}+\frac{1}{\varepsilon_{\mathrm{HOMO}(\text { Ethene })}-\varepsilon_{\mathrm{LUMO}\left(\pi_{6}^{\mathrm{CN}}\right)}}\right]+b
$$

$$
\Delta E_{\mathrm{a}} \approx\left[\frac{1}{\varepsilon_{\mathrm{HOMO}(\text { Ethene) }}-\varepsilon_{\mathrm{LUMO}\left(\pi_{6}^{\mathrm{NN}}\right)}}+\frac{1}{\varepsilon_{\mathrm{HOMO}\left(\pi_{3}^{\mathrm{CN}}\right)}-\varepsilon_{\mathrm{LUMO}(\text { Ethene) }}}\right]+b
$$


Table 2. Interaction energies $(\Delta E, \mathrm{eV})$ between the "frontier" molecular orbitals of nitrilimine and ethene (lowest interaction energies are in boldface type).

\begin{tabular}{llllll}
\hline $\mathrm{R}^{1}$ & $\mathrm{R}^{2}$ & $\Delta E_{\mathbf{A}}{ }^{a}$ & $\Delta E_{\mathbf{B}}{ }^{a}$ & $\Delta E_{\mathbf{C}}{ }^{a}$ & $\Delta E_{\mathbf{D}}{ }^{a}$ \\
\hline $\mathrm{H}$ & $\mathrm{H}$ & -8.14 & $\mathbf{- 6 . 9 9}$ & -7.16 & -7.55 \\
$\mathrm{CH}_{3}$ & $\mathrm{H}$ & -7.56 & $\mathbf{- 6 . 2 4}$ & -7.44 & -8.17 \\
$\mathrm{NH}_{2}$ & $\mathrm{H}$ & -6.69 & $\mathbf{- 6 . 5 5}$ & -6.94 & -9.02 \\
$\mathrm{OH}$ & $\mathrm{H}$ & -7.43 & -6.92 & $\mathbf{- 6 . 2 8}$ & -8.62 \\
$\mathrm{~F}$ & $\mathrm{H}$ & -8.29 & -7.58 & $\mathbf{- 5 . 4 6}$ & -7.68 \\
$\mathrm{H}$ & $\mathrm{CH}_{3}$ & -7.77 & $\mathbf{- 6 . 6 8}$ & -7.22 & -7.67 \\
$\mathrm{H}$ & $\mathrm{NH}_{2}$ & -8.36 & $\mathbf{- 6 . 2 0}$ & -7.21 & -7.90 \\
$\mathrm{H}$ & $\mathrm{OH}$ & -8.87 & $\mathbf{- 6 . 7 1}$ & -7.08 & -6.75 \\
$\mathrm{H}$ & $\mathrm{F}$ & -9.91 & -7.64 & -6.46 & $-\mathbf{5 . 8 1}$ \\
$\mathrm{CH}_{3}$ & $\mathrm{CH}$ & -7.30 & $\mathbf{- 6 . 0 2}$ & -7.38 & -8.07 \\
$\mathrm{NH}_{2}$ & $\mathrm{NH}$ & -7.06 & $\mathbf{- 5 . 8 3}$ & -6.91 & -7.91 \\
$\mathrm{OH}_{2}$ & $\mathrm{OH}$ & -8.08 & -6.74 & $\mathbf{- 6 . 3 2}$ & -7.50 \\
$\mathrm{~F}$ & $\mathrm{~F}$ & -9.99 & -8.33 & $\mathbf{- 4 . 9 0}$ & -5.85 \\
\hline
\end{tabular}

Note: Ethene PBE0/6-311++G(2df,pd) orbital energies: -7.93 eV (HOMO) and $-0.01 \mathrm{eV}$ (LUMO).

${ }^{a} \Delta E_{\mathrm{A}}=\varepsilon_{\left[\pi \pi_{3}^{\mathrm{CN}}\right]_{\text {nitrilimine }}}-\varepsilon_{\mathrm{LUMO}_{\text {ethene }}}, \Delta E_{\mathrm{B}}=\varepsilon_{\left[\pi_{4}^{\mathrm{NN}}\right]_{\text {nitrilimine }}}-\varepsilon_{\mathrm{LUMO}_{\text {ethene }}} ;$

$\Delta E_{\mathbf{C}}=\varepsilon_{\mathrm{HOMO}_{\text {ethene }}}-\varepsilon_{\left[\pi \pi_{5}^{\mathrm{NN}}\right]_{\text {nitrilimine }}}, \Delta E_{\mathbf{D}}=\varepsilon_{\mathrm{HOMO}_{\text {ethene }}}-\varepsilon_{\left[\pi_{6}^{\mathrm{NN}}\right]_{\text {nitrilimine }}}$
(see Scheme 5).

\section{Resonance contributions}

Huisgen (28) recognized early that any molecule that can be ascribed a 1,3-dipolar resonance structure could undergo a [3+2] reaction. Recently, we assessed the weights of the individual resonance contributions of nitrilimine and found that the 1,3-dipolar RS-D and the carbenic RS-C structures (Scheme 1) are the dominant contributors, consistent with the reactivity previously noted $(32)^{4}$.

Relationships between the 1,3-dipolar resonance contribution and the [3+2] $E_{\mathrm{a}}$, and between the carbene resonance contributions and the $[1+2] E_{\mathrm{a}}$, are given in Fig. 4 for the various nitrilimines. As expected, the carbene character of the different nitrilimines is well-correlated $\left(r^{2}=0.987\right)^{8}$ with the $[1+2]$ barrier heights (Fig. $4 a$ ). On the other hand, there is no relationship $\left(r^{2}=0.319\right)$ between the various $[3+2]$ barrier heights and the 1,3-dipolar contribution (Fig. 4b), and even the slope of the trend line is opposite to that expected, suggesting that the 1,3-dipolar resonance structure is not a factor in the observed nitrilimine [3+2] reactivity. Interestingly, contributions from the 1,3-dipolar resonance form (RS-D) show a good correlation $\left(r^{2}=0.935\right)^{8}$ with the nitrilimine [1+2] barrier height (Fig. 4c), with the slope of the trend line opposite to that for the RS-C relationship, implying that an increase in 1,3-dipolar character disfavours the $[1+2]$ pathway.

\section{The nitrilimine cycloaddition mechanism}

Considerable uncertainty still surrounds the 1,3-dipolar cycloaddition mechanism $(1-4,6)$. Two mechanisms have been proposed: $(i)$ a concerted, single-step process with the two new bonds partially formed at the transition state $(8-10$, 60 ); and (ii) a two-step process with initial biradical formation followed by bond rotation and ring closure (11-13). The
Fig. 3. The relationship between orbital interaction energy and reactivity: $(a)$ the [3+2] $E_{\mathrm{a}}$ and the sum of the inverse of the $\mathbf{A}$ and $\mathbf{C}$ orbital interaction energies; $(b)$ the $[1+2] E_{\mathrm{a}}$ and the sum of the inverse of the $\mathbf{C}$ and $\mathbf{D}$ orbital interaction energies; and (c) the difference in [1+2] and [3+2] $E_{\mathrm{a}}$ and the difference in the inverse of the $\mathbf{A}$ and $\mathbf{D}$ orbital interaction energies. Orbital interactions $\mathbf{A}, \mathbf{C}$, and $\mathbf{D}$ are defined in Scheme 5.
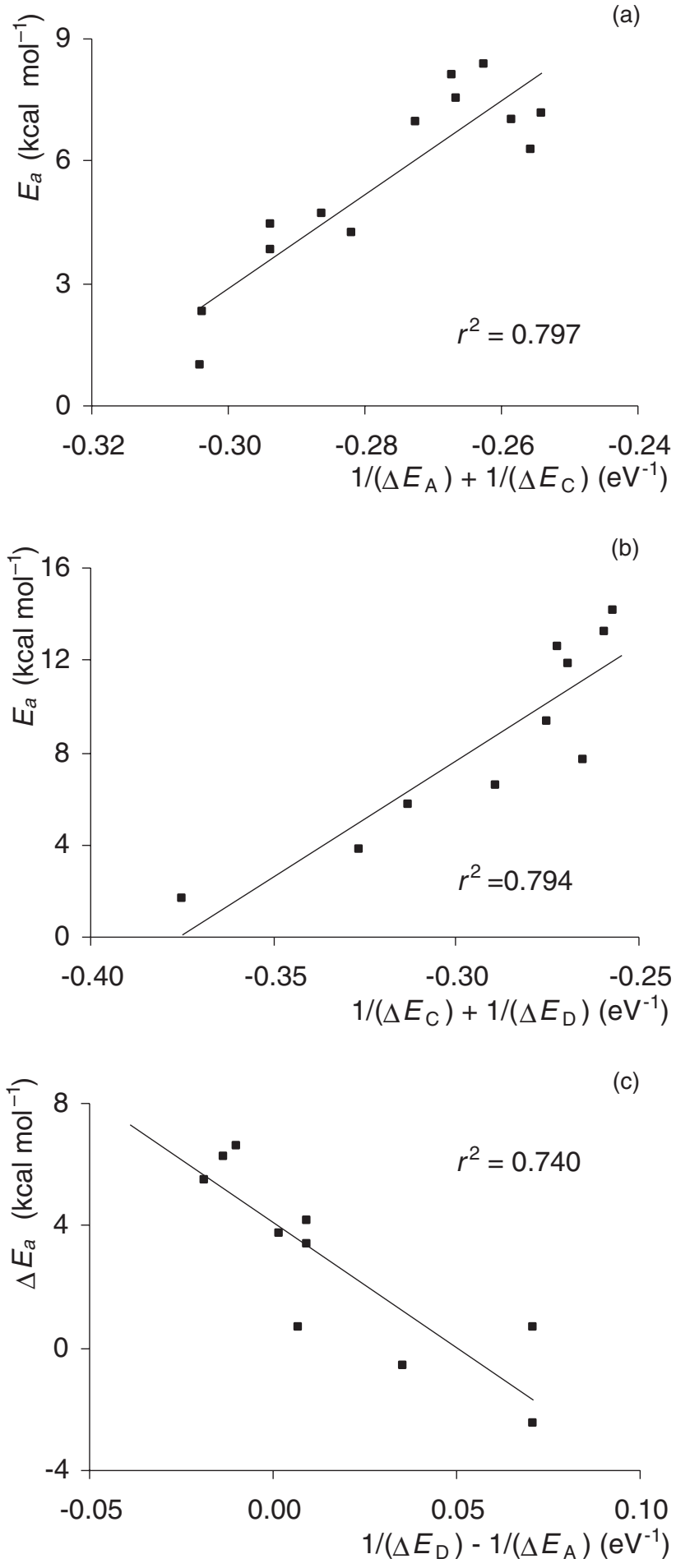

\footnotetext{
${ }^{8}$ These correlation coefficients do not include the outlying point, corresponding to $N$-fluoro substituted nitrilimine, which is believed to be a result of an anisotropic effect noted in the ${ }^{13} \mathrm{C}$ chemical shielding tensor (see footnote 10 ).
} 
Fig. 4. The relationship between reactivity and \% resonance contribution from natural resonance theory for: $(a)$ the $[1+2] E_{\mathrm{a}}$ and the carbenic resonance $(\mathbf{R S}-\mathbf{C})$ contribution $^{8}(b)$ the $[3+2] E_{\mathrm{a}}$ and the dipolar resonance (RS-D) contribution; and $(c)$ the $[1+2]$ $E_{\mathrm{a}}$ and the dipolar resonance (RS-D) contribution. ${ }^{8}$ Resonance structures RS-C and RS-D are depicted in Scheme 1.
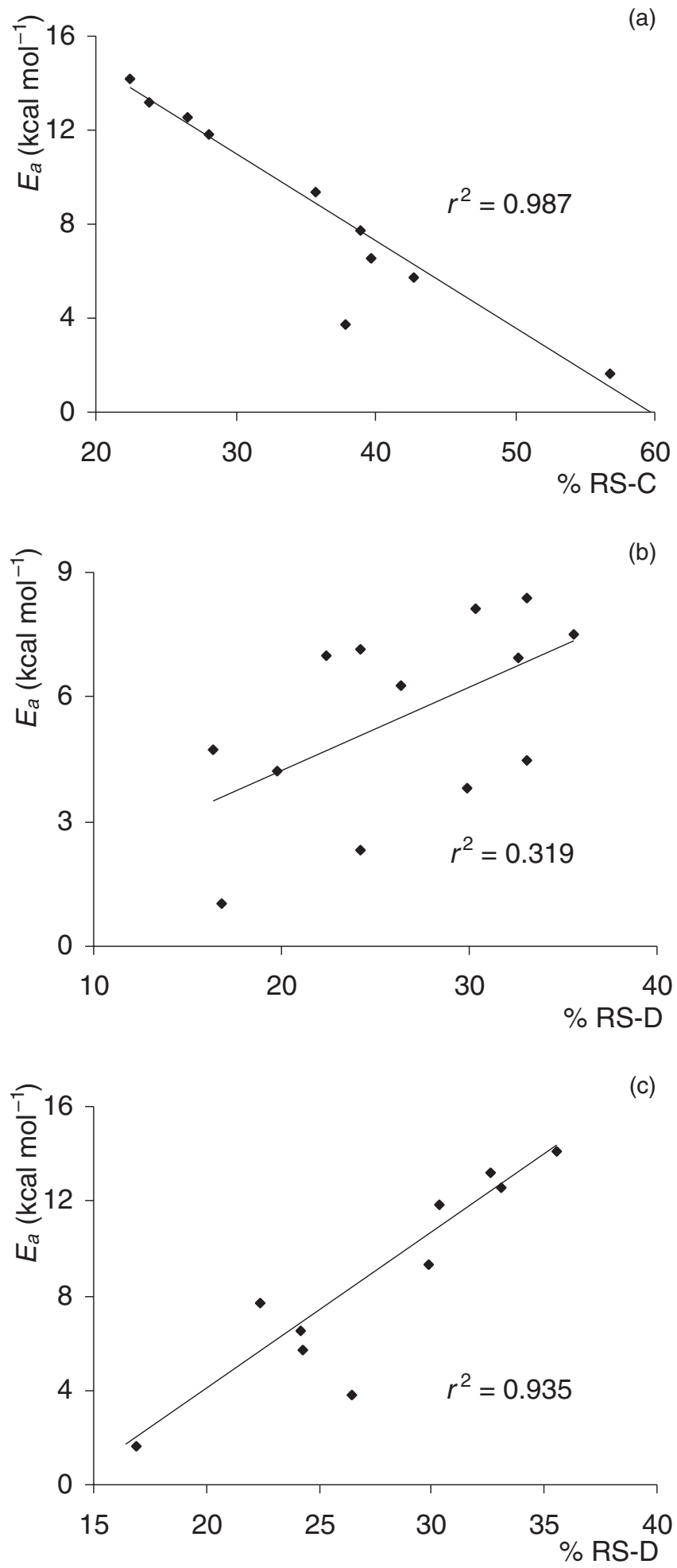

majority of 1,3-dipolar cycloaddition reactions are believed to proceed via a concerted mechanism (23), although there are now several reports of reactions with a biradical mechanism $(1,61-65)$.

For the nitrilimine $[3+2]$ reaction, neither mechanism can be readily adopted. As previously mentioned, all calculated TS structures were stable with respect to a broken-symmetry solution to the wave function and no biradical TS could be located. Therefore, a biradical mechanism must be ruled out. From electronic structure considerations, we noted that $[3+2]$ reactivity was not related to the changes in contributions from the 1,3-dipolar resonance structure, RS-D (Scheme 1), but was partially controlled by FMO interaction A (Scheme 5), formally a carbene-type orbital interaction, and an increase in the RS-D contribution resulted in higher [1+2] reaction barriers. Additionally, the fundamental differences between the two TS structures are the C3-C4 interatomic distance, which is slightly shorter in the [1+2] TS, and the C5-C4-C3-N2 dihedral angle. The difference in the dihedral angle between the two TS structures is linearly dependent $\left(r^{2}=0.842\right)$ on the weight of the RS-C contribution, with the difference diminishing as the \%RS-C increases. Considering that both reaction pathways evolve from the same starting point and the only difference is the orientation of approach (i.e., the C5-C4-C3-N2 dihedral angle), it is not surprising that the $[3+2]$ reaction may involve some characteristics of a [1+2] reaction, especially in the early stages of the reaction. In the following, we suggest that the two reaction paths are not independent, but that the overall mechanism is a combination of the two pathways.

A relaxed potential energy scan was performed for the unsubstituted nitrilimine attacking ethene, varying the C5C4-C3-N2 dihedral angle from $90^{\circ}$ to $0^{\circ}$ and the $\mathrm{C} 3-\mathrm{C} 4$ distance from 2.7 to $2.0 \AA$ (Fig. 5). At large internuclear distances $(2.7 \AA)$, the $[1+2]$ approach is favoured by $0.65 \mathrm{kcal} \mathrm{mol}^{-1}$ and there is a barrier to rotation of $0.85 \mathrm{kcal} \mathrm{mol}^{-1}$ at a dihedral angle of about $15^{\circ}$. As the $\mathrm{C} 3$ - $\mathrm{C} 4$ distance decreases, the barrier to rotation steadily increases, while the location of the barrier shifts to larger dihedral angles. At a C3-C4 distance of $2.0 \AA$, corresponding to the distance at the $[1+2] \mathrm{TS}$, the barrier to rotation is $1.29 \mathrm{kcal} \mathrm{mol}^{-1}$ at a dihedral angle of $50^{\circ}$. The $[1+2]$ pathway is favoured up to about $2.3 \AA$. Beyond $2.3 \AA$, the [3+2] pathway steadily becomes more favourable as product formation begins, while the $[1+2]$ approach results in an increase in energy until the TS at about $2.0 \AA$. Although the calculated energy differences are relatively small and generally within what may be considered the error limits of the model chemistry, it has been shown that the PBE0 functional is capable of reproducing experimental conformational equilibria that are a result of even smaller energy differences (66).

Obviously, many factors have been ignored, such as zeropoint energy corrections and entropic factors, but both pathways should have comparable contributions since they are part of the same bimolecular process. Also, in the initial stages of reaction, the majority of approach trajectories $(\sim 90 \%)^{9}$ result in the [1+2] pathway, highlighting the high statistical probability for this pathway. Therefore, as a general mechanism for nitrilimine cycloadditions, a statistically

\footnotetext{
${ }^{9}$ Only an initial dihedral angle range of $\pm 20^{\circ}$ leads to the [3+2] TS and all other dihedrals lead to the [1+2] TS.
} 
Fig. 5. Relaxed potential energy surface in the vicinity of the two transition states for the reaction between unsubstituted nitrilimine and ethene. (a) Initial carbene-type approach, $(b)$ ridge-bifurcation, and $(c)$ formation of the [3+2] product.

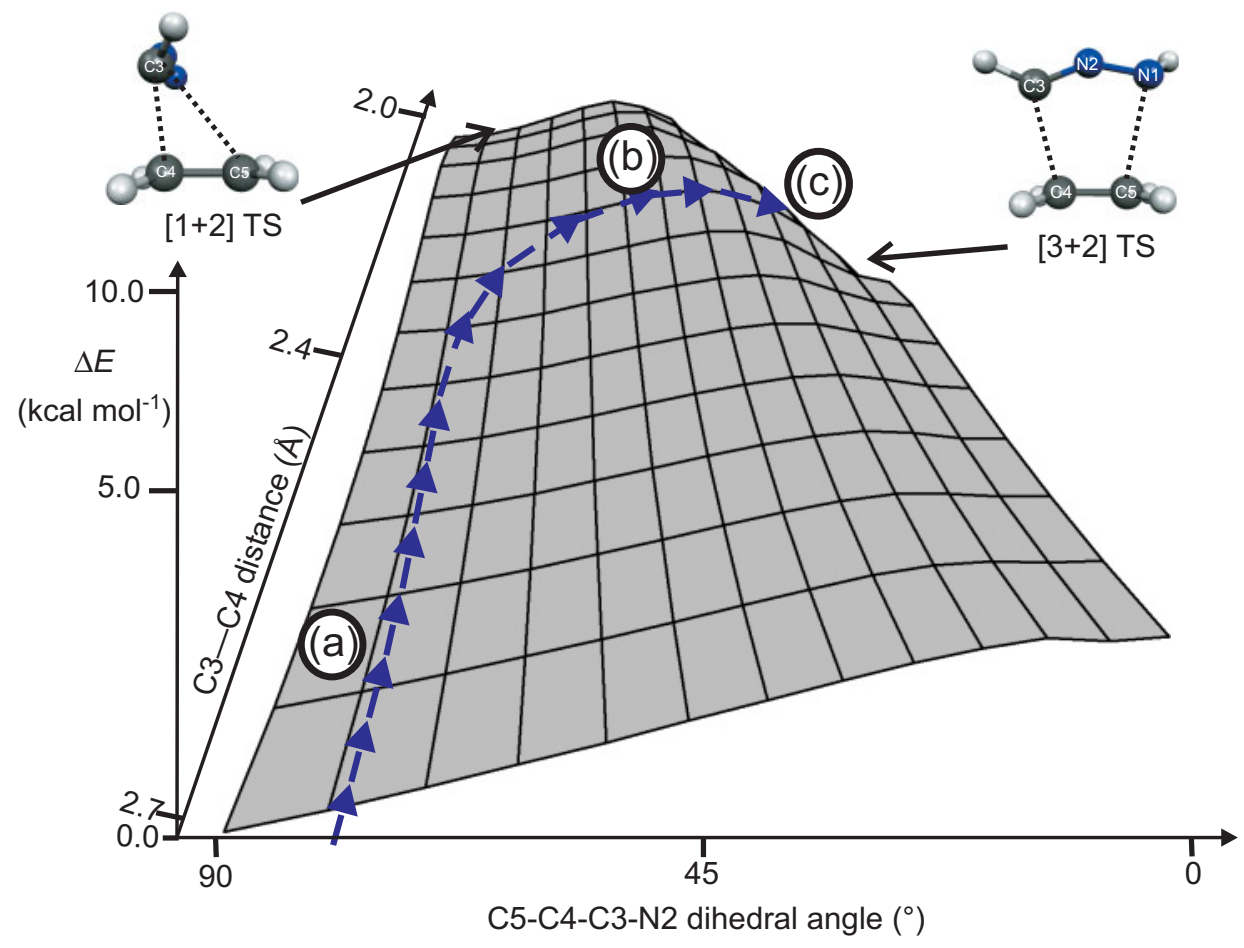

and possibly thermodynamically favoured initial carbenetype attack occurs, up until a specific $\mathrm{C} 3-\mathrm{C} 4$ internuclear distance where the $[3+2]$ reaction pathway becomes favoured, and a ridge-type bifurcation takes place with rotation about the $\mathrm{C} 3-\mathrm{C} 4$ bond axis (Fig. 5). The final product is typically still the thermodynamically, and for the most part kinetically, favoured $\Delta^{2}$-pyrazoline, but the regio- and stereo-selectivity observed in the final product is a result of: (i) the initial carbene-type approach; and (ii) the position of the bifurcation region, which is a function of the difference in barrier heights for the two pathways $\left(\Delta E_{\mathrm{a}}\right)$ and the magnitude of the rotation barrier. Recall that a [1+2] TS structure was not obtained for three systems $\left(\mathrm{R}^{1}=\mathrm{NH}_{2}, \mathrm{R}^{2}=\mathrm{H} ; \mathrm{R}^{1}=\right.$ $\mathrm{R}^{2}=\mathrm{NH}_{2}$; and $\left.\mathrm{R}^{1}=\mathrm{R}^{2}=\mathrm{OH}\right)$. Inspection of the potential energy surface in the region of the $[3+2]$ and $[1+2]$ TSs for these systems reveals that there is no barrier to rotation, hence no ridge-inflection point, and therefore a [1+2] TS cannot be located. For diaminonitrilimine $\left(\mathrm{R}^{1}=\mathrm{R}^{2}=\mathrm{NH}_{2}\right)$, this is fully consistent with its description as a (possibly) stable carbene (32), ${ }^{4,10}$ whose large nucleophilic character prevents its [1+2] addition to electron-rich alkenes.

\section{Conclusion}

Electronic structure calculations reveal that both the [3+2] and $[1+2]$ cycloaddition pathways between ethene and a series of nitrilimines have low barriers and large reaction exothermicities, consistent with the transient nature of nitrilimines. In the majority of cases, the $[3+2]$ reaction is preferred, but the [1+2] pathway can be favoured by varying the N-substituents. Both reactions proceed with concerted, asynchronous mechanisms, with the $[1+2]$ pathway exhibit- ing a greater degree of asynchronicity. The geometries of the $[1+2]$ and $[3+2]$ TSs are similar and the fundamental difference lies in the orientation of the approaching reactants, i.e., the $\mathrm{C} 5-\mathrm{C} 4-\mathrm{C} 3-\mathrm{N} 2$ dihedral angle. The [3+2] reaction barrier is controlled by two orbital interactions, one of which is carbene-like in nature, and the [1+2] barrier is related to the interaction between the HOMO of ethene and the two unoccupied $\pi$ orbitals of nitrilimine. The potential energy surface in the vicinity of the [3+2] and [1+2] TSs reveals that the initial phase of the reaction corresponds to a carbene-like attack of the nitrilimine, which after crossing a ridge-inflection region of the surface, eventually results in the formation of the $[3+2]$ product. Further work is currently being carried out to examine the effects of ethene substitution and to design experiments that can confirm our proposed mechanism.

\section{Acknowledgements}

This research was supported by a Nouveaux ChercheursÉquipe grant from the Fonds Québecois de Recherche sur la Nature et les Technologies (FQRNT). Calculations were performed at the Centre for Research in Molecular Modeling (CERMM), which was established with the financial support of the Concordia University Faculty of Arts and Science, the Ministère de l'Éducation du Québec (MEQ), and the Canada Foundation for Innovation (CFI). G.H.P. holds a Concordia University Research Chair.

\section{References}

1. S. Sakai and M.T. Nguyen. J. Phys. Chem. A, 108, 9169 (2004).

\footnotetext{
${ }^{10}$ R.C. Mawhinney, H.M. Muchall, and G.H. Peslherbe. Submitted for publication.
} 
2. V. Polo, J. Andres, R. Castillo, S. Berski, and B. Silvi. Chem. Eur. J. 10, 5165 (2004).

3. M.J. Aurell, L.R. Domingo, P. Perez, and R. Contreras. Tetrahedron, 60, 11503 (2004).

4. P. Perez, L.R. Domingo, A.J. Aurell, and R. Contreras. Tetrahedron, 59, 3117 (2003).

5. G. Molteni and A. Ponti. Tetrahedron, 59, 5225 (2003).

6. K. Sakata. J. Phys. Chem. A, 104, 10001 (2000).

7. M.D. Su, H.L. Liao, W.S. Chung, and S.Y. Chu. J. Org. Chem. 64, 6710 (1999).

8. R. Huisgen. Angew. Chem. Int. Ed. Engl. 2, 633 (1963).

9. R. Huisgen. J. Org. Chem. 33, 2291 (1968).

10. R. Huisgen. J. Org. Chem. 41, 403 (1976).

11. R.A. Firestone. J. Org. Chem. 33, 2285 (1968).

12. R.A. Firestone. J. Org. Chem. 37, 2181 (1972).

13. R.A. Firestone. Tetrahedron, 33, 3009 (1977).

14. R.A. Firestone. Heterocycles, 25, 61 (1987).

15. R. Huisgen, M. Seidel, J. Sauer, J.W. McFarland, and G. Wallbillich. J. Org. Chem. 24, 892 (1959).

16. R. Huisgen, R. Grashey, M. Seidel, R. Schmidt, H. Knupfer, and G. Wallbillich. Ann. Chem. 653, 105 (1962).

17. R. Huisgen, H. Knupfer, R. Schmidt, M. Seidel, and R. Grashey. Ann. Chem. 658, 169 (1962).

18. R. Huisgen, R. Grashey, M. Seidel, H. Knupfer, and R. Kunz. Chem. Ber. 97, 1085 (1964).

19. R. Huisgen, K. Adelsberger, E. Aufderhaar, H. Knupfer, and G. Wallbillich. Monatsh. Chem. 98, 1618 (1967).

20. R. Huisgen and E. Aufderhaar. Chem. Ber. 98, 2185 (1965).

21. K. Marakchi, O.K. Kabbaj, N. Komiha, and M.L. Charibi. J. Fluorine Chem. 109, 163 (2001).

22. A.F. Jalbout, Z. Jiang, H. Abou-Rachid, and N.N. Benkaddour. Spectrochim. Acta Part A, 60, 603 (2004).

23. K.N. Houk, J. Gonzalez, and Y. Li. Acc. Chem. Res. 28, 81 (1995).

24. J.T. Sharp. In The Chemistry of heterocyclic compounds 59: Synthetic applications of 1,3-dipolar cycloaddition chemistry toward heterocycles and Natural products. Edited by A. Padwa and W.H. Pearson. John Wiley and Sons, New York. 2002. pp. 473-537.

25. G. Bertrand and C. Wentrup. Angew. Chem. Int. Ed. Engl. 33, 527 (1994).

26. F. Palacios, J. Pagalday, V. Piquet, F. Dahan, A. Baceiredo, and G. Bertrand. J. Org. Chem. 62, 292 (1997).

27. F. Foti, G. Grassi, and F. Risitano. Synlett, 125 (2005).

28. R. Huisgen. Angew. Chem. Int. Ed. Engl. 2, 565 (1963).

29. S.D. Kahn, W.J. Hehre, and J.A. Pople. J. Am. Chem. Soc. 109, 1871 (1987).

30. M.W. Wong and C. Wentrup. J. Am. Chem. Soc. 115, 7743 (1993).

31. K. Kuhler, R.T. Palmer, B.L. Wittkamp, and M.R. Hoffmann. THEOCHEM, 360, 41 (1996).

32. R.C. Mawhinney, H.M. Muchall, and G.H. Peslherbe. Chem. Commun. (Cambridge), 1862 (2004).

33. E.D. Glendening and F. Weinhold. J. Comput. Chem. 19, 593 (1998).

34. E.D. Glendening and F. Weinhold. J. Comput. Chem. 19, 610 (1998).

35. E.D. Glendening, J.K. Badenhoop, and F. Weinhold. J. Comput. Chem. 19, 628 (1998).

36. M.J. Jones and R.A. Moss. In Reactive intermediate chemistry. Edited by R.A. Moss, M.S. Platz, and M.J. Jones. John Wiley and Sons Inc., Toronto. 2004. pp. 273-328.

37. D. Bourissou, O. Guerret, F.P. Gabbai, and G. Bertrand. Chem. Rev. 100, 39 (2000).
38. R.A. Moss. Acc. Chem. Res. 13, 58 (1980).

39. N.G. Rondan, K.N. Houk, and R.A. Moss. J. Am. Chem. Soc. 102, 1770 (1980).

40. S. Sakai. Int. J. Quantum Chem. 70, 291 (1998).

41. A.E. Keating, S.R. Merrigan, D.A. Singleton, and K.N. Houk. J. Am. Chem. Soc. 121, 3933 (1999).

42. J.J. Blavins, D.L. Cooper, and P.B. Karadakov. Int. J. Quantum Chem. 98, 465 (2004).

43. D.C. Merrer and P.R. Rablen. J. Org. Chem. 70, 1630 (2005).

44. M.J. Frisch, G.W. Trucks, H.B. Schlegel, G.E. Scuseria, M.A. Robb, J.R. Cheeseman, V.G. Zakrzewski, J.A. Montgomery, Jr., R.E. Stratmann, J.C. Burant, S. Dapprich, J.M. Millam, A.D. Daniels, K.N. Kudin, M.C. Strain, O. Farkas, J. Tomasi, V. Barone, M. Cossi, R. Cammi, B. Mennucci, C. Pomelli, C. Adamo, S. Clifford, J. Ochterski, G.A. Petersson, P.Y. Ayala, Q. Cui, K. Morokuma, N. Rega, P. Salvador, J.J. Dannenberg, D.K. Malick, A.D. Rabuck, K. Raghavachari, J.B. Foresman, J. Cioslowski, J.V. Ortiz, A.G. Baboul, B.B. Stefanov, G. Liu, A. Liashenko, P. Piskorz, I. Komaromi, R. Gomperts, R.L. Martin, D.J. Fox, T. Keith, M.A. Al-Laham, C.Y. Peng, A. Nanayakkara, M. Challacombe, P.M.W. Gill, B. Johnson, W. Chen, M.W. Wong, J.L. Andres, C. Gonzalez, M. Head-Gordon, E.S. Replogle, and J.A. Pople. GAUSSIAN 98. Revision A.11.4 [computer program]. Gaussian, Inc., Pittsburgh Penn. 2002.

45. J.P. Perdew, K. Burke, and M. Ernzerhof. Phys. Rev. Lett. 77, 3865 (1996).

46. J.P. Perdew, K. Burke, and M. Ernzerhof. Phys. Rev. Lett. 78, 1396 (1997).

47. J.P. Perdew, M. Ernzerhof, and K. Burke. J. Chem. Phys. 105, 9982 (1996).

48. W.J. Hehre, R. Ditchfield, and J.A. Pople. J. Chem. Phys. 56, 2257 (1972).

49. M.M. Francl, W.J. Pietro, W.J. Hehre, J.S. Binkley, M.S. Gordon, D.J. DeFrees, and J.A. Pople. J. Chem. Phys. 77, 3654 (1982).

50. C. Gonzalez and H.B. Schlegel. J. Chem. Phys. 90, 2154 (1989).

51. C. Gonzalez and H.B. Schlegel. J. Chem. Phys. 95, 5853 (1991).

52. G.S. Hammond. J. Am. Chem. Soc. 77, 334 (1955).

53. K.N. Houk, J. Sims, C.R. Watts, and L.J. Luskus. J. Am. Chem. Soc. 95, 7301 (1973).

54. R. Sustmann. Pure Appl. Chem. 40, 569 (1974).

55. R.A. Moss. Acc. Chem. Res. 22, 15 (1989).

56. K.N. Houk, J. Sims, R.E. Duke, R.W. Strozier, and J.K. George. J. Am. Chem. Soc. 95, 7287 (1973).

57. L. Salem. J. Am. Chem. Soc. 90, 543 (1968).

58. L. Salem. J. Am. Chem. Soc. 90, 553 (1968).

59. W.C. Herndon. Chem. Rev. 72, 157 (1972).

60. R. Huisgen. Pure Appl. Chem. 53, 171 (1981).

61. Y. Yoshioka, D. Yamaki, S. Kiribayashi, T. Tsunesada, M. Nishino, K. Yamaguchi, K. Mizuno, and I. Saito. Electron. J. Theor. Chem. 2, 218 (1997).

62. Y. Yoshioka, D. Yamaki, S. Kubo, M. Nishino, K. Yamaguchi, K. Mizuno, and I. Saito. Electron. J. Theor. Chem. 2, 236 (1997).

63. C. Di Valentin, M. Freccero, R. Gandolfi, and A. Rastelli. J. Org. Chem. 65, 6112 (2000).

64. R. Sustmann, W. Sicking, and R. Huisgen. Chem. Eur. J. 9, 2245 (2003).

65. R. Sustmann, W. Sicking, and R. Huisgen. J. Am. Chem. Soc. 125, 14425 (2003).

66. R.C. Mawhinney, H.M. Muchall, and J. Lessard. Can. J. Chem. 81, 1101 (2003). 